\title{
Transport of anthropogenic and biomass burning aerosols from Europe to the Arctic during spring 2008
}

L. Marelle et al.

Correspondence to: L. Marelle (louis.marelle@latmos.ipsl.fr) 


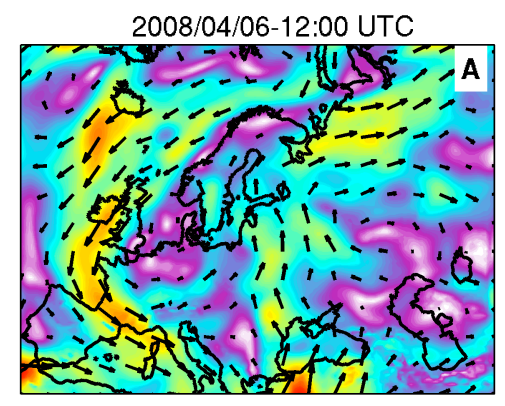

2008/04/08-12:00 UTC

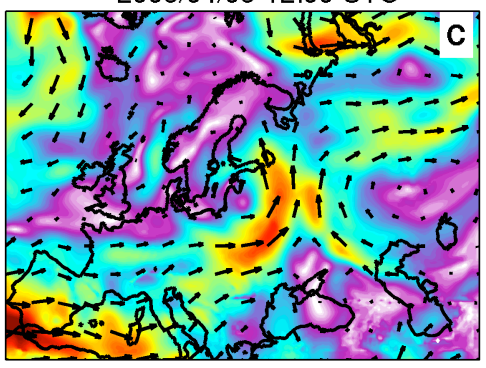

2008/04/10-12:00 UTC

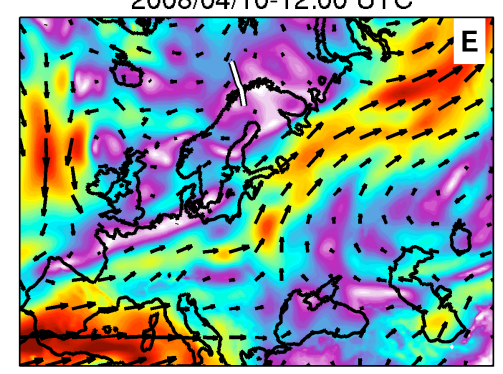

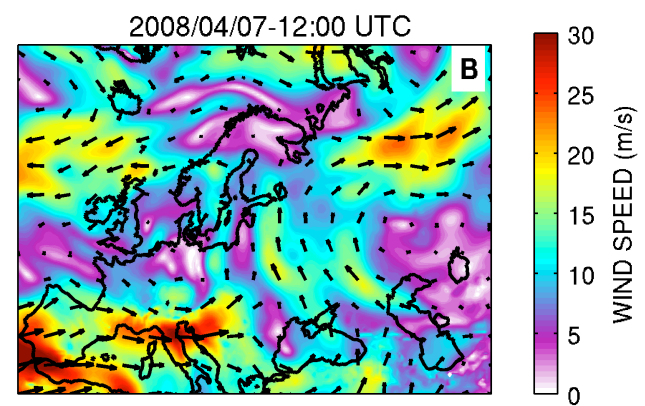

2008/04/09-12:00 UTC

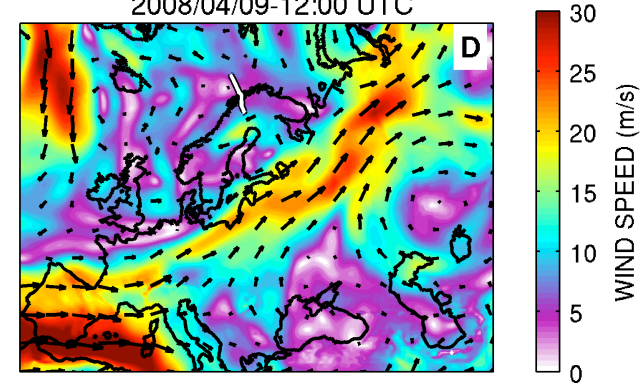

2008/04/11-12:00 UTC

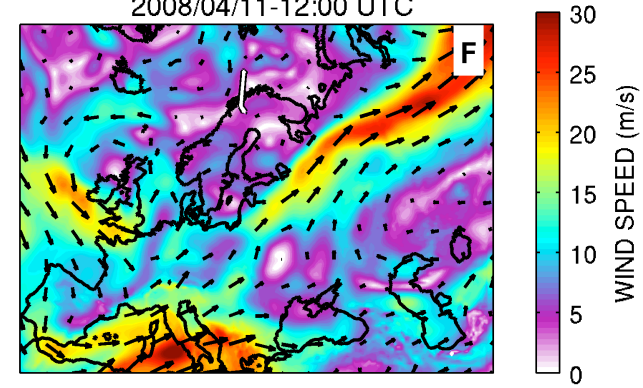

Figure S1. $700 \mathrm{hPa}$ wind speed with arrows showing wind direction on 6, 7, 8, 9, 10 and 11 April at 12 UTC. POLARCAT-France flight tracks are shown for the 9, 10 and 11 April flights on panels D, E, F respectively (in white). 

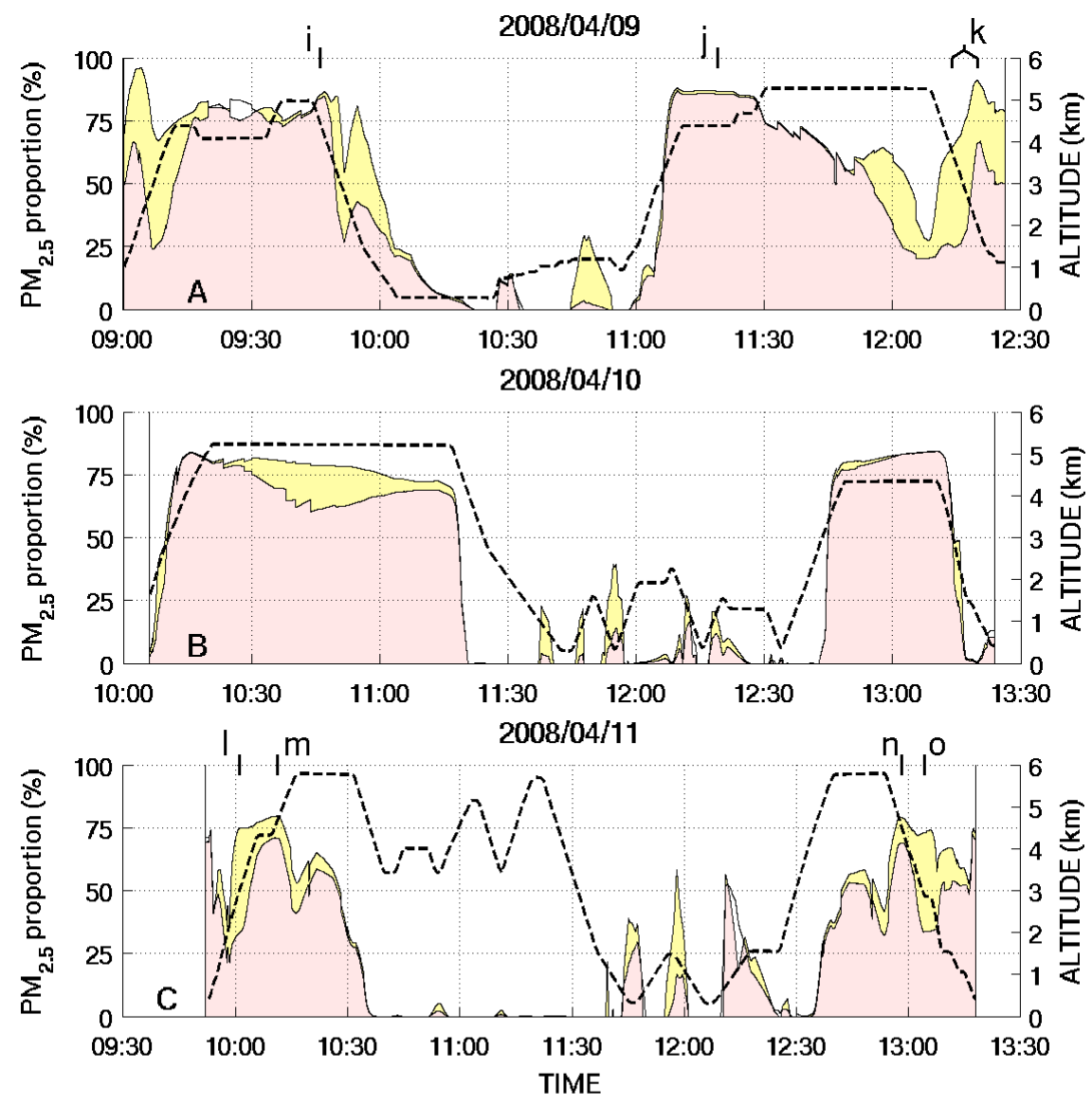

ALTITUDE

ANTHRO.

FIRES

OTHER SOURCES

Figure S2. Stacked area plot representing the percentage of total $\mathrm{PM}_{2.5}$ attributed to anthropogenic (pink) and fire (yellow) emissions, along the POLARCAT-France spring flight tracks. Plane altitude is in black. (A) 2008/04/09 flight (B) 2008/04/10 flight (C) 2008/04/11 flight. Letter labels indicate anthropogenic (I, J, M, N) and mixed anthropogenic/fire (K, L, O) plumes investigated further. 
BOUNDARY CONDITION PLUME : 2008/04/10-12:40
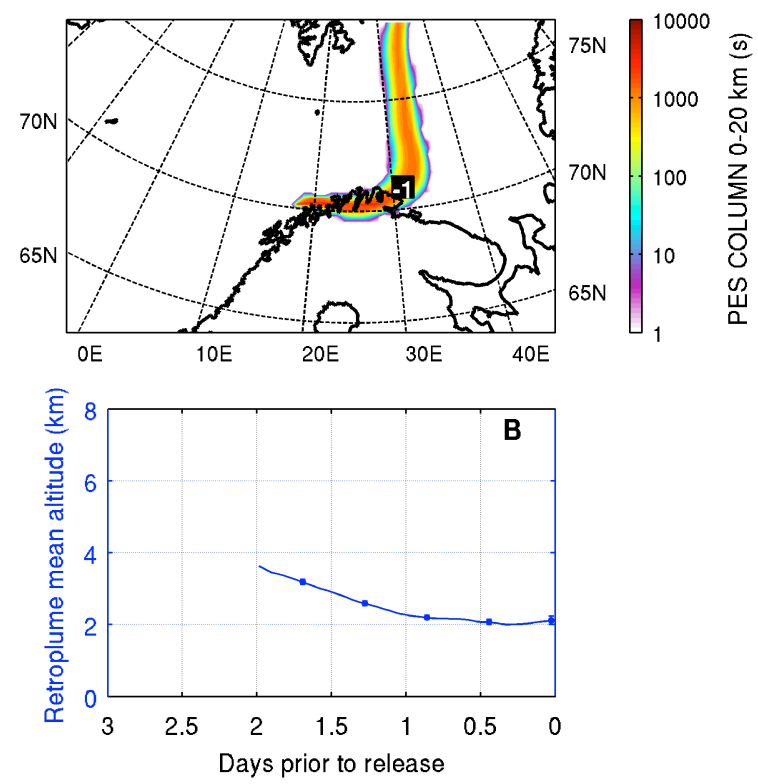

Figure S3. Backward mode FLEXPART-WRF simulation showing typical transport pathways for a boundary condition plume (originating on the $2008 / 04 / 10$, at $12 \mathrm{~h} 40$ UTC on the flight track). (A) Column integrated PES, (B) plume mean altitude with RMS error bars. 

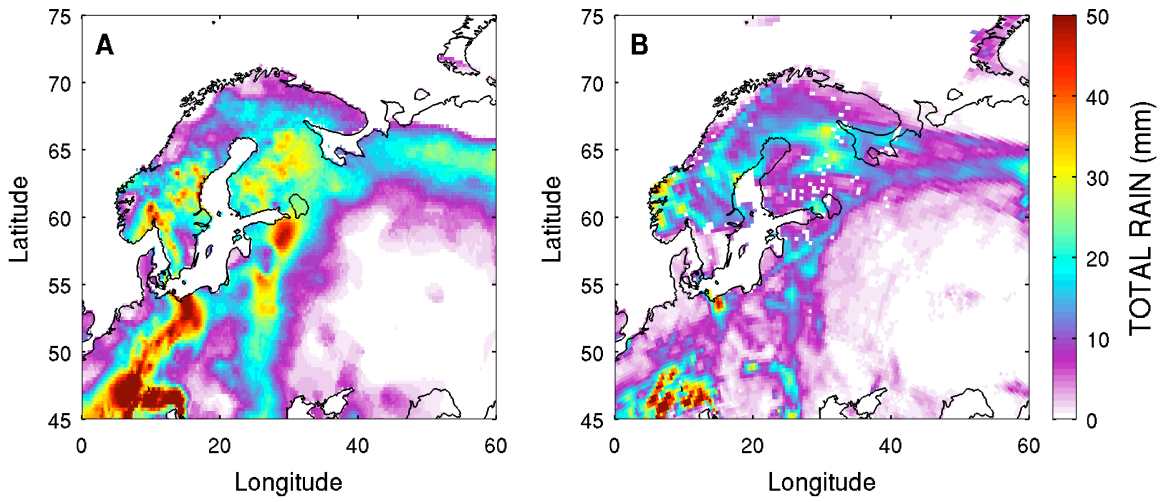

Figure S4. Total accumulated rain between 4 April 20080 UTC and 12 April 20080 UTC (A) in the ECA E-OBS $0.25^{\circ}$ gridded dataset (B) in WRF-Chem (CTL). An ocean mask (also masking inland lakes) has been applied to the map in panel B. 


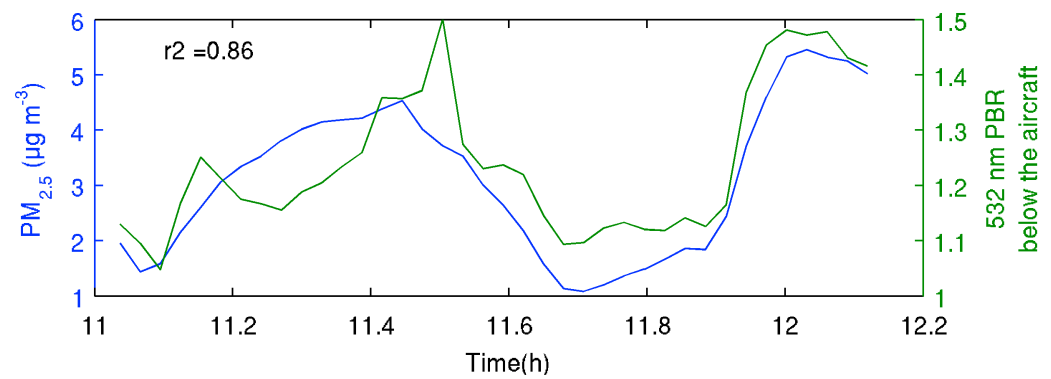

Figure S5. Measured $\mathrm{PM}_{2.5}$ (blue) and LIDAR Pseudo Backscatter Ratio (PBR) at $532 \mathrm{~nm}$ close below the aircraft (green) between 11:00 UTC and 12:12 UTC during the 9 April 2008 flight. 


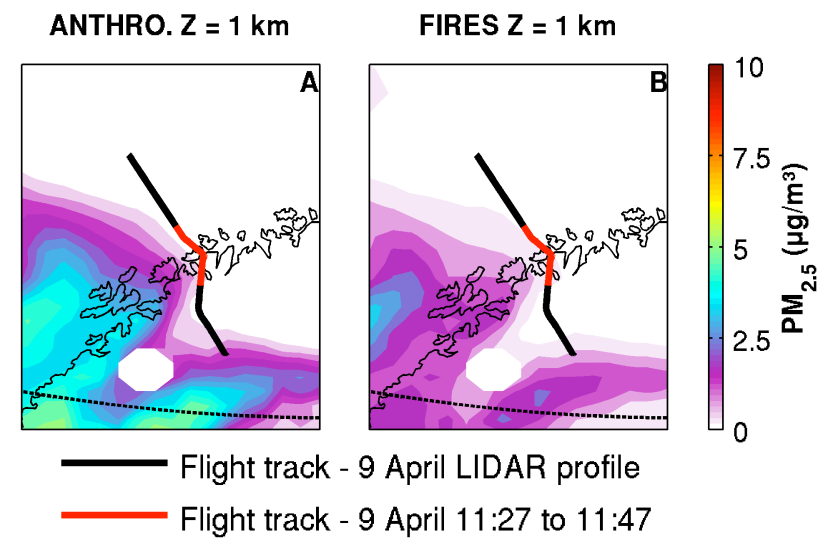

Figure S6. Map of anthropogenic (A) and fire (B) $\mathrm{PM}_{2.5}$ sections at $1 \mathrm{~km}$, on 9 April 2008 at 12 UTC. The flight track during the LIDAR profile shown in figure 10 is shown in black, and the part of the flight (from 11:27 to 11:47) when an aerosol plume was measured by LIDAR at $1 \mathrm{~km}$ is highlighted in red. 